\title{
Treba li Crkva voljeti (Božji) svijet? Odgovor na sedmu točku Capetownskog iskaza o predanju
}

\author{
Gregory S. Thellman \\ Visoko evanđeosko teološko učilište, Osijek \\ greg.thellman@evtos.hr
}

UDK:2-284;2-46;274/278

Izvorni znanstveni članak

https://doi.org/10.32862/k1.14.1.3

\section{Sažetak}

Ovaj je rad odgovor na sedmu točku, podtočke A) i B) Capetownskog iskaza o predanju (CIOP), a cilj mu je pokušati odgovoriti na pitanje: "Je li ljubav pravilna kršćanska reakcija na stvorenje izvan ljudskog roda i/ili na ljudske narode i kulturu? Na temelju sažetka koncepcija kao što su ljubav i svijet u biblijskom tekstu, pokazujemo kako biblijska koncepcija ljubavi kategorično ističe duboku i brižnu posvećenost drugoj osobi unutar međuljudskih, odnosno odnosa između Boga i čovjeka. "Svijet" u Svetom pismu može imati pozitivno, neutralno ili negativno značenje, ovisno o pojmu i kontekstu, a kršćani pripadaju i posrnulom stvorenju koje iščekuje oslobođenje, kao i ljudskim narodima u kulturama koje su u grijehu i pobuni protiv Boga. Premda Biblija nigdje ne zapovijeda vjernicima da vole stvorenje izvan ljudskog roda niti kolektivne ljudske entitete kao što su narodi i kulture, kršćani mogu izraziti ljubav prema Bogu i bližnjemu u obliku brige za stvorenje i kao svoj doprinos kulturi na način koji će proslaviti Boga. Tako kršćani mogu "voljeti" stvorenje i kulturu, ali isključivo u zavisnosti od temeljne ljubavi usmjerene na Boga i bližnjega.

Ključne riječi: kršćanstvo, ljubav, svijet, stvorenje, kultura, novo stvorenje 


\section{Uvod}

Sedma točka Capetownskog iskaza o predanju (CIOP) iz 2011. naslovljena je

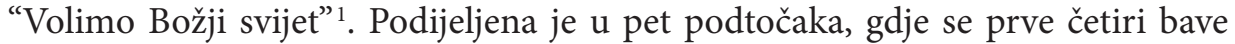
konkretnim područjima "Božjeg svijeta" koji trebamo voljeti: A) "Božji svijet stvorenja" s fokusom na ono što nazivamo svijetom prirode, B) "Božji svijet naroda i kultura", odnosno, kolektivni ljudski entiteti i njihove osobine, kao i ljudska kreativnost, C) "siromašni i napaćeni u svijetu" i D) naši "bližnji" (koje trebamo voljeti kao same sebe). Posljednja podtočka E) upozorava na onaj svijet koji ne trebamo voljeti, odnosno "svijet ljudske i sotonske pobune protiv Boga."

Od svih točaka CIOP-a, sedma je točka možda jedina koja bi mogla biti problematična. Ne bi trebalo biti kontroverzi vezano uz poziv da volimo samoga trojedinoga Boga, kao i Njegovu Riječ, Njegove vjerne, pa čak i Evanđelje i Božju misiju, što su točke 1-6 i 8-10. Čak i u točkama C) i D) spomenute sedme točke, voljeti bližnjega kao samoga sebe, osobito one najranjivije, jasne su biblijske zapovijedi. Međutim, postoje izvjesni problemi - ili barem nejasnoće - u prve dvije podtočke A) i B), jer one kao da idu dalje od velike zapovijedi da volimo Boga i bližnjega (Mt 22,36-40). Stoga, u ovom ću članku nastojati propitati ove dvije podtočke i razmotriti treba li Crkva zbilja voljeti onaj dio stvorenog svijeta koji ne obuhvaća ljude te treba li zbilja voljeti svijet ljudskog izričaja i kreativnosti, koji se ispoljava u ljudskim narodima i kulturama.

Da bismo odgovorili na ova pitanja, prvo moramo razmotriti dva glavna pojma iz naslova sedme točke - "voljeti" i "svijet" - u Svetom pismu. Obje koncepcije nose širok spektar značenja, kako u današnje vrijeme, tako i u biblijskoj uporabi, te mogu zavarati u dokumentu kratkom poput CIOP-a. Zato ću najprije razmotriti biblijsku uporabu ovih dvaju pojmova i njihove različite nijanse i naglaske. Cilj mi je razjasniti ove koncepcije kako bih mogao položiti temelj za konačan zaključak o tome poziva li Pismo Crkvu zbilja na to da voli svijet stvorenja izvan ljudskog roda i svijet ljudske kulture i kreativnosti.

\section{Traženje "ljubavi" u Bibliji}

U suvremenom engleskom jeziku riječ "ljubav" može se odnositi na razne bliske odnose među ljudima, kao i na sklonost koju osoba može imati prema drugim živim ili neživim stvarima, aktivnostima, idejama i raspoloženjima. Uglavnom,

1 https://www.lausanne.org/content/ctcommitment\#p1-7. Ovaj članak je adaptacija odgovora na sedmu točku Capetownskog iskaza o predanju u sklopu panel-diskusije Evanđeoskog teološkog društva (ETD) u Hrvatskoj održane u Zagrebu 10. lipnja 2019. 
zamišlja je se kao emociju, ${ }^{2}$ često kao osjećaj koji se nekome "događa”, poput doživljaja romantične ljubavi, ili poput prirodnoga emocionalnog nagona kao što je ljubav prema djetetu i članovima obitelji, odnosno osobne preferencije prema zadovoljstvu.

Premda biblijski pojam obuhvaća neke od ovih elemenata, jasno je da ističe "ljubav" koja se odlikuje krepošću i aktivnom predanošću u odnosima, kako među ljudima tako i između Boga i ljudi. U hebrejskoj Bibliji nalazimo dva pojma koji se uglavnom prevode kao "ljubav": 'ahavah (glaglol 'ahav) i hesed. Prvi je pojam općenitija riječ za "ljubav" koja obuhvaća više podznačenja od romantične ljubavi, ljubavi među članovima obitelji, ljubavi među prijateljima, ljubavi prema narodu, ljubavi prema Bogu i, rijetko, uživanju u drugim stvarima. I sam Bog ispoljava 'ahavah' prema pojedincima i prema cjelokupnom Izraelu, a pojedini teolozi smatraju da je takva ljubav zapravo Božja "ljubav prema izabranima" (Snaith 1964, 133), odnosno Njegova bezuvjetna i vječna ljubav (Routledge 2012, 110).

Drugi pojam, hesed, koji se prevodi kao "nepokolebljiva ljubav" (engl., "steadfast love" u prijevodu ESV) obuhvaća mnoge ideje kao što su ljubav, vjernost, dobrota, milost, milosrđe i trajno predanje, što je dovelo do više različitih prijevoda. Možemo zaključiti da je hesed relacijska, uzajamna i okrenuta djelima (Routledge 1995, 181-82). Premda nije lišena emocija, hesed ističe posvećenu predanost uzajamnoj brizi. Iako se ova koncepcija uglavnom koristi za definiranje predanih međuljudskih odnosa, ona još više odlikuje Božju predanu zavjetnu ljubav prema Njegovu narodu i reakciju ljubavi koja se očekuje od njih. Budući da je hesed pojam koji se tiče međusobnih odnosa, on se uvijek događa među ljudima, odnosno između Boga i ljudi, a kao što to barem neki teolozi tvrde, to se uvijek događa u kontekstu zavjetnog dogovora, bilo među ljudima ili između Boga i Njegova naroda (Snaith 1964, 95; Glueck 1967, 102).

Ipak, čak i kad je riječ o 'ahavah', ono što bismo mogli nazvati "bezuvjetnom ljubavlju” kad je riječ o Božjoj ljubavi (Routledge 2012, 110), većina slučajeva opisuje ljubavlju među ljudima, odnosno između Boga i ljudi. U manjem broju slučajeva, gdje predmet ljubavi nisu ni Bog ni ljudi, ljubav se odnosi samo na osobnu preferenciju prema zadovoljstvu, ${ }^{3}$ sklonost određenim ljudskim osobinama (bile one pozitivne ili negativne) ili na Izraelovu ljubav k tuđinskim običajima, tuđim narodima i tuđim bogovima, što je misao koja je vrlo prisutna kod klasičnih proroka, koji često opisuju Izrael u odnosu s metaforičkim stranim ljubavnicima, što se uvijek smatra negativnim odnosom (Jer 2,25.33; 3,1; 22,20-22; Tuž 1,2.19;

2 Valja napomenuti da Cambridgeov internetski rječnik (pristupljeno 16. ožujka, 2020. https:// dictionary.cambridge.org/dictionary/english/love) definira glagol "voljeti" prvenstveno kao romantičnu i seksualnu privlačnost, dok imenicu "ljubav" prvenstveno opisuje kao "osjećaj".

3 Primjerice, Izakova ljubav prema određenoj hrani, kao što čitamo u Postanku 27. 
Ez 16,33-37; 23,5-22; Hoš 2,5-15). Sveto pismo Starog zavjeta zapovijeda nam samo da volimo Boga (Pnz 6,5), da volimo druge ljude, osobito bližnje koji su unutar zavjetne zajednice (Lev 19,18) i strane putnike (Lev 19,34; Pnz 10,1819). Mada je Izraelcima zapovjeđeno da vole pripadnike stranih naroda, koji se zateknu među njima, njihova sklonost i želja, odnosno njihova ljubav tuđim entitetima i njihovim putovima ( $\mathrm{tj}$., njihovim kulturama) uvijek se smatra negativnom, poglavito zato što su one bile po naravi povezane sa štovanjem lažnih bogova.

Starozavjetne mudrosne knjige, kao i velik dio proročkih govora, u pravilu odbacuju ljubav prema ljudskim zadovoljstvima (Izr 21,17), bogatstvu (Prop 5,10), prijestupima (Izr 17,19), prijevari (Ps 52,3; Zah 8,17), snazi jezika (Izr $18,21)$ i drugim sličnim porocima, oblicima ponašanja i apstraktnim idejama kao što je zlo (Ps 52,3), u isti mah afirmirajući ljubav prema Božjim propisima, svjedočanstvima, obećanjima i zapovijedima (Ps 119) te pravdi, kao i apstraktnim idejama kao što su istina i mir (Zah 8,19), i ljudskim osobinama kao što su znanje (Izr 12,1), discipliniranje (Izr 12,1), čistoća srca (Izr 22,11) i druge vrline. Ovi bi tekstovi mogli implicirati da, u onoj mjeri u kojoj ljudske zajednice i kulture podupiru i potvrđuju ove druge osobine i odriču se onih prvih, takve ljudske kulturološke izričaje možemo "voljeti". Međutim, bolje je zaključiti da zapravo u metaforičnom smislu volimo same ideje i vrline, koje su produžetak Božjeg karaktera ili su ukorijenjene u taj stvoreni poredak.

Vrlo je malo primjera gdje se govori da trebamo "voljeti" neki aspekt prirodnog svijeta. Čitamo da je kralj Uzija volio zemlju (2 Ljet 26,10), što se navodi kao razlog za njegovu bogatu gradnju i poljoprivredni razvoj. I dok se možda smatralo da su kraljevske građevinske aktivnosti "znak božanskog blagoslova" (Dillard 1987, 208), ne vidimo da narator iznosi bilo kakav sud o "ljubavi prema zemlji" te se čini kako se jednostavno radi o izjavi o osobnom zadovoljstvu u obavljanju nekog posla, a ne o plemenitoj brizi za okoliš. Jeremija 8,2 ukazuje na to da su vođe Jeruzalema voljeli nebeska tijela. Međutim, ovdje se očito radi o negativnom sudu jer su nebeska tijela predstavljala lažne bogove kojima su se oni što ih je prorok osudio klanjali (vidi Pnz 4,19; 17,3).

Nema dvojbe da se u Svetom pismu Starog zavjeta stvorenje izvan ljudskog roda smatra veoma dobrim (Post 1; vidi Jer 31,35) i vrijednim divljenja (Job 3839; Ps 104), i da je Bog zadao ljudskom rodu zadaću da brine i upravlja nad njime (Post 1,$28 ; 2,15)$. Nadalje, jasno je da i sam Bog brine o svojem stvorenju, čak i nakon pada (Post 7-9; Jona 4,11), da mu se i sam divi (Job 38-39; Ps 104,31) i da suvereno vlada nad njime na blagoslov svojem zavjetnom narodu (Pnz 7,13-14). Konačno, cjelokupno Sveto pismo Starog zavjeta potvrđuje da je YHWH Stvoritelj neba i zemlje, po čijoj suverenoj moći sve postoji i kome sve pripada (Iz 19,5; Ps 89,11; vidi Moo i Moo 2018, 64-65). Ipak, unatoč svemu tome, nigdje ne 
nalazimo izričitu zapovijed da volimo prirodni svijet izvan ljudskog roda. Čak i veličanstvo stvorenja kojem se divimo služi kako bi nas potaklo da hvalimo samoga Stvoritelja, a ne stvorenje (Ps 8,3-4; 104,1-2). Stari zavjet mnogo govori o tome kako ljudi trebaju pokazivati ljubav i prema Bogu i prema drugim ljudima.

Ista su načela prisutna i u grčkom Novom zavjetu, doduše sada uvjetovana novim savezom u Kristu. Većina spominjanja u Novom zavjetu također su poziv na ljubav prema Bogu, ljubav prema bližnjemu i ljubav među vjernicima unutar zajednice kršćana, što se gotovo uvijek izražava grčkom riječju agapē (glagol: agapāo), odnosno rjeđe glagolom phileō (imenica philia, samo u Jak 4,4). ${ }^{4}$ Teolozi često diferenciraju ova dva pojma. Ovaj drugi općenito se odnosi na privrženost u obiteljskim i prijateljskim odnosima, odnosno na ljubav prema određenim stvarima, bez "jasnoga religijskog naglaska" (Günther i Link 1986, 2:538), a u Novom zavjetu na "ljubav prema ljudima koji su blisko povezani, bilo krvnim srodstvom ili vjerom" (Günther i Link 1986, 2:542). Agapē, međutim, što je grčki prijevod hebrejskoga 'ahavah, prema Staufferu (1964, 1:37), jest ljubav koja slobodno bira i posvećuje se svojem predmetu, umjesto da je određuju postojeće zavjetne ili obiteljske veze, odnosno druge prirodne sklonosti. U tom smislu odgovara hebrejskome 'ahavah, koji se u Septuaginti dosljedno prevodi kao ljubav koja bira. Međutim, to ne znači da je agapē isključivo odluka i postupanje na temelju te odluke. Kao što Carson $(2000,646)$ tvrdi, način na koji Pavao koristi taj izraz u 1. Korinćanima 13 pokazuje da je agape "snažnija nego. . . Puka želja za dobrobiti drugoga”, čime se implicira da mora sadržavati određene osjećaje.

Nadalje, čini se da se u izvjesnim slučajevima dva grčka pojma za ljubav koriste kao istoznačnice (Iv 3,$35 ; 5,20 ; 21,15-17)$ pa Carson $(2000,646)$ upozorava da ih ne treba previše diferencirati. ${ }^{5}$ Brown $(1986,2: 548-49)$ isto tako zaključuje da u novozavjetnoj uporabi pojmova phileō i agapaō "nema striktnog razgraničenja među njima” (npr., vidi Lk 11,43 i 20,46) iako ima slučajeva gdje se zadržava izvorno značenje (Mt 10,37). Zato ću u nastavku tretirati sve novozavjetne odjeljke gdje se govori o ljubavi bez diferenciranja grčkih pojmova, što je pristup koji je zadovoljavajući za općenite ciljeve ovog rada.

4 Postoje još dva grčka pojma za ljubav koje ne nalazimo u Novom zavjetu: erōs (erāo), koji se može sažeti kao "svijet koji traži zadovoljenje gdje god može" (Stauffer 1964, 1:37), ali je najpoznatiji kao romantična ili spolna ljubav i strast; te glagol stergō, koji se obično odnosi na ljubav među roditeljima i djecom, odnosno na druge hijerarhijske odnose (Günther i Link 1986, 2:539). Ovaj drugi u Novom zavjetu nalazimo samo u sklopljenom izrazu u Rimljanima 12,10 .

5 Kao što Carson primjećuje, Septuaginta u 2 Sam 13 koristi i agapaō i phileō kad govori o Amnonovom incestuoznom silovanju Tamare iako bismo očekivali erōs. 
Isusovo učenje ponavlja načela istaknuta u hebrejskome Svetom pismu: ljubav prema Bogu i bližnjemu (Mt 22,34-40 // Mk 12,29-31; Lk 10,27) te među Njegovim učenicima (Iv 13,34-35), na čemu se i dalje izričito inzistira u ostalim knjigama Novoga zavjeta (Rim 13,9; Gal 5,14; 1 Sol 4,9; Jak 2,8). Međutim, Isus ide i dalje, pozivajući nas da volimo čak i neprijatelje (Mt 5,43). To je u skladu sa životom i službom samoga Isusa, koji je volio čak i one koji su Mu htjeli oduzeti život, a produžetak je Božje zavjetne ljubavi prema Izraelu koja je u Starom zavjetu već bezgranična, čak i onda kad je Izrael neposlušan.

Međutim, kad predmet ljubavi nisu Bog ni drugi ljudi, sud naratora uglavnom je negativan, pa "kada je agapē očito usmjerena k stvarima. . sama uporaba. . . treba nam jasno dati do znanja da je usmjerena na nešto pogrešno, odnosno ne na Boga" (Günther i Link 1986, 2:543). Ljudi ne trebaju voljeti novac (Mt 6,24; Lk 6,13; 1 Tim 6,10), zadovoljstva (2 Tim 3,4), vlastitu čast (Mt 6,5; Lk 11,43; Iv $12,43)$ niti "tamu" (Ivan 3,19). Katkad su ovi negativni sudovi izraženi nasuprot pozivanju na ljubav prema Bogu (2 Tim 3,4) ili pojedinim vrlinama (2 Sol 2,10; 2 Tim 3,2). Zanimljiva stavka za usporedbu jest ljubav prema sebi, koja može biti pozitivna (Mt 22,39; Rim 13,9), ali i negativna (Iv 12,25; 2 Tim 3,2), ovisno o tome jesmo li uzdigli ljubav prema sebi iznad Boga i drugih ljudi (negativno) ili imamo ispravan pogled na nju u odnosu na ljubav prema Bogu i bližnjemu (pozitivno). Ovo opažanje ukazuje nam na značajno biblijsko načelo o ljubavi: ljubav prema Bogu uvijek je na prvome mjestu i predstavlja temelj, nakon nje slijedi ljubav prema drugima te prema sebi. Međutim, i dalje ne nalazimo imperativ, nema konkretne upute koja bi ukazivala na ljubav prema stvorenju izvan ljudskog roda niti ljudskim nacionalnim entitetima i kulturama. Dapače, imamo brojne zapovijedi da ne trebamo voljeti svijet (2 Tim 4,10; 1 Iv 2,15).

\section{Sagledavanje "svijeta" u Bibliji}

Poput ljubavi, i riječ "svijet” u Svetom pismu obuhvaća razna značenja i nijanse, tako da izraz "Božji svijet", koji se koristi u CIOP-u, nije bez problema. U hebrejskom Pismu merizam "nebo i zemlja" (Post 1,1; Izl 31,17; Jer 33,25) predstavlja ukupnost i poredak svega što je Bog stvorio (Waltke 2001, 59), što posjeduje (Post 14,19-22) i što Ga proslavlja (Ps 69,34). Drugi pojmovi prevedeni kao "svijet" jesu ḥeled ("svijet"), a još češće, u pjesničkoj literaturi, tevel, koji se odnosi na nešto poput suhe zemlje ili čvrstog tla, svijeta kao jedinstvenog entiteta (Wright 1997, 272-73) ili kao "kruga zemaljskog iz drevne bliskoistočne kozmologije" (Fabry and van Meeteren 2006, 558). Ovi pojmovi, dakle, govore o svijetu kao Božjem stvorenju premda Izaija (primjerice, 13,11) govori konkretno o tevelu, jer će mu YHWH suditi. Hebrejski pojam erets, premda se katkad spominje uz tevel (Ps 90,2; Jer 51,15), ali ipak znači nešto sličnije "naseljenoj zemlji” nego cjeloku- 
pni čvrsti svijet. Čini se da Stari zavjet ne koristi pojam "svijet" u smislu entiteta koji se protivi Bogu, nego u smislu Božjeg stvorenja, nad kojim Bog suvereno vlada, posjeduje ga i održava ga (Ps 50,12; 89,11; 1 Ljet 16,30), a koji je, pak, isto podložan Božjem sudu (Ps 96,13; Iz 26,9). ${ }^{6}$

U Novom zavjetu nalazimo brojne načine izražavanja raznih ideja koje se kriju iza pojma "svijet", od kojih su neke pozitivne, neutralne i negativne kad je riječ o odnosu svijeta prema Bogu. Koncepcija "svijeta" može se izraziti pomoću četiri relevantna grčka izraza i jednom frazom: kosmos, što se prevodi kao "svijet"; aiōn, što se katkad prevodi kao "svijet"; oikoumenā, također se prevodi kao "svijet"; ktisis, što se prevodi kao "stvorenje"; gēe, prevodi se kao "zemlja" i, kao i u Starom zavjetu, merizam ho ouranos kai hē gēe, "nebo i zemlja".

Merizam "nebo i zemlja" često funkcionira slično načinu na koji se koristio u Starom zavjetu, gdje se njime izražava sadašnje, sveobuhvatno stvorenje svega što postoji, osim samoga Boga (Mt 5,$18 ; 24,35) .{ }^{8} \mathrm{Ge}$ je prilično uobičajen samostalno, a odgovara hebrejskome erets te, ovisno o kontekstu, može se odnositi na zemlju kao cjelinu, na određenu državu ili jednostavno na tlo, odnosno zemlju (Painter 2013, 1014-16). Na sličan način Ktisis odražava prirodni svijet Božjeg stvorenja, koji je sad posrnuo i podložan je iskvarenosti, ali iščekuje obnovu (Rim 8,18-23) koja obuhvaća čovječanstvo jedino utoliko što je i čovjek dio prirodnog stvorenja (Mk 10,6; Kol 1,23). Oikoumenā se odnosi na cjelokupni nastanjeni svijet, što obuhvaća i ljude (Mt 24,14; Rim 10,18), ali bez nebeskih prostranstava i podzemlja (BDAG, 699). Premda oikoumenā može biti prevarena (Otk 12,9) i patiti (Luka 21,26), čini se da je ipak predmet zla, a ne da predstavlja zlo kao takvo. Svaki od ovih izraza, popraćen karakterističnim nijansama, odnosi se na Božje stvorenje te funkcionira u neutralnom, a možda čak i pomalo pozitivnom smislu (osobito Rim 8,18-23) kad je riječ o odnosu prema Bogu.

Kosmos se, isto tako, može odnositi na prirodno stvorenje, nastanjeni svijet ( Rim 1,8), odnosno na cjelokupno čovječanstvo u neutralnom smislu (1 Kor 1,28; 1 Kor 14,10; Kol 1,6), kao što može predstavljati i cjelokupni stvoreni svemir (Rim 1,20; Ef 1,4; Heb 4,3). Međutim, mnogo češće odnosi se na putove čovječanstva, i to u vrlo negativnom smislu (2 Kor 7,10; Gal 4,3) ili se odnosi na cjelokupnost

6 Pojam adamah, koji se prevodi kao "zemlja, blato", može se odnositi i na cjelokupno suho tlo u pojmu "lice zemlje" (Iz 23,17).

7 Premda se aiōn katkad prevodi kao "svijet" (Mt 13,22; Marko 4,19), pojam doslovno znači "doba” i treba ga promatrati sa stajališta dva doba židovskoga apokaliptičkog pogleda na svijet. U tom smislu, aiōn donekle odgovara ideji o "svijetu" kao sustavnoj sferi koja se protivi Bogu u ovom vremenu prije konzumacije (vidi u nastavku).

8 Nisu sve uporabe ovih dviju imenica merizmatične; katkad funkcioniraju i antitetički (Mt 6,10; $16,19 ; 18,18)$. Korisnu diskusiju o ovoj razlici, osobito s obzirom na Evanđelje po Mateju, vidi kod Penningtona (2009, 163-215). 
grešnog čovječanstva (Heb 11,7; 2 Pet 2,20; 1 Iv 2,16 i brojni drugi), sadašnje grešno doba (Ef 2,2), postojanje pod vlašću Sotone (1 Iv 5,19), kraljevstvo koje se protivi Božjem kraljevstvu (Otk 11,15) ili na duhovnu stvarnost koja se protivi Bogu (1 Kor 2,12). U velikom broju slučajeva Novi zavjet jasno postavlja kosmos nasuprot Bogu. A opet, kosmos, koji predstavlja grešna ljudska bića ili možda cjelokupno fizičko stvorenje, jest ono što Bog voli (Iv 3,16-17), zbog čega je poslao Krista da ga otkupi i spasi (Rim 11,15; 1 Tim 1,15). ${ }^{9}$

S jedne strane, Pismo priznaje i navješćuje konačno vlasništvo i zakonitu vlast Boga kao stvoritelja, otkupitelja i eshatološkog obnovitelja nad svime što postoji (Iza 37,16; Mt 11,25). S druge, pak, strane Pismo isto tako prepoznaje čovjekovo posrnulo stanje (Post 3), koje je ostavilo trajne posljedice na stvorenje (Rim 8,1823), kao i na Božje dopuštanje privremene vladavine svjetovnih kraljevstava koja Mu se protive (Ps 46,6; Iz 10,10; 23,17; Dan 7-8) te "vlasti i poglavarstava", tj., nadnaravnih sila (1 Kor 15,24; Ef 1,1;2,2) koje se sustavno ostvaruju unutar ljudske vlasti i kulture. Stoga, kad Novi zavjet govori o sadašnjem aiōnu, odnosno dobu, u nekim slučajevima ga se prevodi kao "svijet" (vidi napomenu 7), gdje se radi o sadašnjem sustavnom, kolektivnom pobunjeništvu ljudi i duhovnih sila protiv Boga, što je dovelo stvoreni red u stanje posrnulosti, bolesti i smrti (Lk 16,8; Iv 9,32; Rim 12,2; Gal 1,4). Ovo je privremeno stanje možda najočitije u izvješću o Isusovoj kušnji, gdje đavao tvrdi da ima "sva kraljevstva svijeta" (Mt 4,8-9; Lk 4,5-6), što je misao koja je usko vezana uz apokaliptično stajalište kakvo nalazimo u Danielovoj knjizi $(10,13 ; 12,1)$. Potkraj Matejeva evanđelja uskrsli Isus izjavljuje da posjeduje "svu vlast na nebu i zemlji" (Mt 28,18-20), ${ }^{10}$ ali strategija kojom želi ostvariti svoj autoritet jest podizanje učenika, odnosno izgradnja Njegove crkve čak i u ovom sadašnjem (grešnom) dobu, do doba koje ima doći. U Poslanici Efežanima Krist je prikazan kako pobjedonosno sjedi nad vlastima svijeta u sadašnjoj realnosti (Ef 1,21 ), ali ove vlasti ipak i dalje imaju utjecaja u ovom sadašnjem, zlom dobu (Ef 5,16; vidi Gal 1,4), odnosno u "ovom mračnom svijetu" (Ef 6,12).

Možda se zbog toga čini kao da je naglasak u Novom zavjetu na upozoravanju Božjeg naroda da se ne prilagođava ovom svijetu (kosmos) u ovome dobu, umjesto da ga voli. ${ }^{11}$ Pavao piše da ga je Dema napustio jer je bio "zaljubljen u

9 Što se tiče ljubavi (phileō), Brown (1986, 2:548) smatra da Evanđelje po Ivanu "određuje ljubav ovisno o tome gledamo li na svijet kao na Božje stvorenje ili kao na sferu koja se protivi Bogu”. Kad je riječ o prvom značenju, "ljubav prema stvorenju" je opravdana (Iv 11,3.36), ali kad se radi o drugom značenju, ljubav prema svijetu isto je što i mržnja prema Bogu (Iv 15,19).

10 Funkciju "neba i zemlje" u ovom odjeljku najbolje ćemo shvatiti kao spoj antitetskih sfera neba i zemlja, a ne kao puki merizam. Vidi Pennington (2009, 210-11).

11 U tekstovima iz ovog odjeljka relevantni pojam jest kosmos. 
sadašnji svijet” (2 Tim 4,10), što je jasna asocijacija na povratak grčko-rimskom načinu životu, koji se protivi Kristovoj crkvi (vidi Ef 2,11-12). Ivan nam piše da ne volimo svijet niti stvari koje su od svijeta (1 Iv 2,15), a Jakov nas upozorava da ne budemo prijatelji svijetu (Jak 4,4). U ovim je slučajevima jasno da voljeti svijet znači pružiti svoju najveću naklonost i privrženost sferi ljudskog stvorenja i moći koja je povezana s bezbožnim duhovnim silama, a ne s istinskim Bogom Stvoriteljem, jer tada ne volimo svijet s ciljem da ga otkupimo, nego zato što se želimo prilagoditi njegovim mjerilima i uživati u njegovim zadovoljstvima.

U Starom zavjetu, kao što smo vidjeli, isto načelo vrijedi za odnos između Izraela i njegovih susjeda. Zanimljivo je napomenuti da Bog u Starom zavjetu zapovijeda Izraelcima da pokazuju ljubav prema stranim došljacima koji traže utočište $\mathrm{u}$ Izraelu, ali $\mathrm{u}$ isti mah opominje Izrael zbog toga što prima strane "ljubavnike", a to je očito metafora za ljubav prema stranim običajima, među kojima i prema štovanju lažnih bogova u vidu idolopoklonstva, što je dovodilo do razvrata i često se povezivalo s njime (npr., $\mathrm{Br} 25$ ). Isto možemo zaključiti i na temelju novozavjetnih spisa. Vjernici su upozoreni da ne ljube svijet (kosmos) kao sferu koja se protivi Bogu i često je povezana s pobunjenim duhovnim silama i lažnim štovanjem, ali su isto tako pozvani da vole grešne ljude koji su u svijetu, makar im bili i neprijatelji.

Međutim, izgleda da CIOP preokreće ovaj naglasak u sedmoj točki, uz članak od samo četiri retka u podtočki E) na "svijet koji ne trebamo voljeti”. Ipak, upravo je to ono značenje riječi "svijet", tj., one ljudske institucije, kulture i strukture koje se nalaze izvan Crkve i ispoljavaju neprijateljstvo prema Bogu, koje je u Novom zavjetu najučestalije. ${ }^{12}$ Kad je riječ o stvorenju izvan ljudskog roda, Rim 8,18-23 i drugi odjeljci ističu da Bog zbilja želi obnoviti svoje, isprva dobro, stvorenje, koje je sada, zbog grijeha, podložno propadanju, i načiniti novo stvorenje na temelju otkupiteljskog čina Isusa Krista. Međutim, ostaje činjenica da se u Pismu ističe ljubav prije svega prema Bogu, a potom prema drugim ljudima, a nikad izričito prema stvorenju izvan ljudskog roda niti kolektivnim ljudskim entitetima i kulturama.

\section{Treba li Crkva voljeti svijet stvorenja izvan ljudskog roda?}

Postoje utjecajni pravci u evanđeoskim krugovima koji su barem napola gnostični u pogledu stvorenog svijeta, koji uopće ne vide neku osobitu vrijednost

12 Što se tiče vlasti, neki tekstovi (Mt 22,21; Rim 13,6-7) potvrđuju da je poštovanje i poslušnost političkim ustanovama od Boga dano sredstvo za održavanje poretka, ali ne sugerira da trebamo voljeti vlasti kao ustanovu. 
u svijetu koji nas okružuje i smatraju "nebo" bijegom za bestjelesne ljude nakon smrti, odbacujući ili zanemarujući biblijsko učenje o novom stvorenju i uskrsnuću. S druge strane, u trenutačnom kulturološkom zeitgeistu kršćani se moraju čuvati sentimentalne ili panteističke ljubavi prema prirodnom svijetu, na koju CIOP s pravom upozorava pod točkom 7A, tvrdeći da kršćani zapravo trebaju brinuti o stvorenju jer ono pripada Bogu. Odnosno, ljubav kršćana prema svijetu treba se oslanjati na njihovu primarnu ljubav prema Bogu. I, opet, premda Pismo ne sadrži izričitu zapovijed da vjernici trebaju voljeti stvorenje (izvan ljudskog roda), ljudskom je rodu ipak u Postanku 1-2 jasno zapovjeđeno da brine o vrtu i vlada nad stvorenjem koje je Bog stvorio kao "veoma dobro". Moo i Moo (2018, 51) smatraju da Božja procjena s početka pruža cijelom stvorenju njegovu unutarnju vrijednost. Uz to, kao što smo vidjeli, čudesnost Božje kreativne moći i ljepote Njegova stvorenja izražena je u brojnim biblijskim tekstovima, posebice u Psalmima. Očito je da se negiranje dobrote stvorenja protivi samoj srži biblijske teologije i Božjega stvoriteljskog identiteta. Nebriga za ono što je Bog stvorio i proglasio dragocjenim znači ne voljeti samoga Boga i izravno je kršenje zapovijedi danih prvim ljudima u Postanku 1-2.

Međutim, trebaju li kršćani zbilja izravno "voljeti” stvorenje izvan ljudskog roda? Iako Pismo proslavlja ljepotu stvorenja, ono to čini tako da proslavi Boga, a ne same stvorene stvari. Psalam 104, pjesma koja na veličanstven način prikazuje ljepotu stvorenja i Božji užitak u njemu (vidi Izr 8,30), oboje počinje i završava izričitom hvalom Bogu, a ne njegovu stvorenju. Stoga, moramo istaknuti da se naputci o ljubavi prema stvorenju moraju izričito nadovezivati na ljubav prema Bogu Stvoritelju, da se ne bi pretvorila u idolopoklonstvo. Ljubav je u Bibliji djelatna riječ koja obuhvaća i osjećaj i posvećenost Bogu, odnosno drugom ljudskom biću. Shodno tomu, zapovijed iz Postanka o vladavini nad svime što je Bog stvorio, premda povremeno katastrofalno pogrešno tumačena, treba u temelju pokazivati da su djela brige prema stvorenju jedan od načina na koji Božji narod iskazuje ljubav prema Bogu jer je povezanost između ljubavi prema Bogu i poslušnosti protkana kroz cjelokupan kanon Svetog pisma (Izl 20,6; Pnz 7,9; Neh 1,5; Dan 9,4; Iv 14,15.21; 15,10; 1 Iv 5,2; 2 Iv 6).

Također, vrijedi imati na umu da i mi ljudi spadamo pod stvorenje. Iako je stvaranje ljudi jasno prikazano kao kruna cjelokupnog stvorenja na šesti dan u Postanku 1, ljudi su ipak stvoreni istog dana kada i ostale kopnene životinje (Post 1,24-31) i stvoreni su "od praha" (Post 2,7). U Rimljanima 8,18-23 Pavao pokazuje kako je stvorenje u cjelini po svojoj naravi povezano s ljudima jer i samo stvorenje uzdiše od čežnje za otkrivenjem “sinova Božjih". Obnova čovječanstva iz grešnog, posrnulog stanja odrazilo se na cijelo prirodno stvorenje, što nas upućuje na realnost novog stvorenja. Eshatološki govoreći, bolje prepoznavanje vrijednosti Božjeg stvorenja i stvorenog poretka pomoći će kršćanima u prepoznavanju 
buduće svrhe novog stvorenja: novih nebesa i zemlje (Iz 65,17; 66,22; Otk 21,1). I premda možda nećemo moći u potpunosti precizno definirati novo stvorenje niti utvrditi u kojem je smislu ono slično ili različito od sadašnjega stvorenog poretka, Isusovo uskrsnuće nam pruža obrazac $i$ za kontinuitet $i$ za diskontinuitet. Kao što će uskrsli ljudi, poput uskrslog Isusa, koji je prvi uskrsnuli (1 Kor 15,20), i dalje biti utjelovljeni ljudi, ali s misterioznim proširenjem moći i sposobnosti unutar ljudskog tijela koje će u potpunosti pokretati Božji Duh (1 Kor 15,35-49), tako će se i novo stvorenje izvan ljudskog roda odlikovati kontinuitetom i diskontinuitetom. Ako smo sada istinski zadivljeni pred Božjim stvorenjem, ljepota i moć koji nas čekaju u novom svijetu bit će zbilja veličanstveni.

Ipak, valja imati na umu da, prema Pavlovim riječima u Rimljanima 8, ovaj novi svijet ne treba shvaćati kao potpuno nov i izvan kontinuiteta sa sadašnjim prirodnim svijetom, nego da se odnosi na Božje "veoma dobro" stvorenje - koje je trenutačno podložno ropstvu propasti - koje će se osloboditi "robovanja pokvarljivosti da sudjeluje u slobodi i slavi djece Božje" (Rim 8,21). Brinuti za prirodno stvorenje znači brinuti za stvorenje koje će Bog osloboditi, stvorenje kojem i mi stvoreni pripadamo (Moo i White 2014, 114), koje će nakon obnove obuhvaćati otkupljenje u našim vlastitim tijelima (Rim 8,23; Fil 3,21).

Nadalje, briga za stvoreni svijet također je čin ljubavi prema bližnjemu. Kao što Moo i Moo $(2018,186)$ tvrde, "stvorenje" obuhvaća "okolinu u kojoj ljudi žive", što će "imati ogromnog utjecaja na njihovu dobrobit". Ugrubo objašnjeno na manjoj razini, ne bismo li se svi složili da to nikako ne bi bila ljubav prema bližnjemu kad bismo bacali smeće preko ograde, u bazen s pijeskom u kojem se njegovo dijete igra? Onda je na većoj razini razumno zaključiti da će naše savjesno ophođenje prema stvorenju utjecati na naše bližnje blizu i daleko, na buduće naraštaje, kao i na nas same. Ipak, Moo i Moo $(2018,185)$ tvrde da, iako je ljubav prema bližnjemu bitna u našem ophođenju sa stvorenim poretkom, "kršćanima je u konačnici stalo do stvorenja, ne iz vlastitih interesa, pa čak niti iz ljubavi prema drugima, nego zato što je to Božje stvorenje”. Možemo ilustrirati ovo načelo vlastitim iskustvom, makar i nesavršeno. Možemo se diviti i biti skloni nekom predmetu koji nam je s ljubavlju načinila voljena osoba zbog kvaliteta koje on sam po sebi posjeduje, ali naša djela ljubavi i brige prema tom predmetu u biti se temelje na našoj ljubavi prema voljenoj osobi, a ne prema samom predmetu, koliko god on bio divan ili koristan. Voljeti predmet umjesto voljene osobe koja ga je načinila i podarila nam ga bilo bi izopačeno. "Volimo" predmet zato što volimo osobu, stoga je u pitanju produžetak naše primarne ljubavi, to je ljubav koja se oslanja, odnosno kao što CIOP (7A) izjavljuje: "logičan ishod naše ljubavi prema Bogu iskazan u vidu brige prema onome što Mu pripada."

Stoga, mogli bismo odgovoriti na pitanje iz naslova pozitivno, ako bi "ljubav" prema stvorenju izvan ljudskog roda bila stav predanosti stvorenom fizičkom 
svijetu, koji rezultira u djelima brižne ljubavi za njega i sklonosti prema njegovoj ljepoti i korisnosti, stav koji je ukorijenjen i ovisan o našoj primarnoj, predanoj relacijskoj ljubavi prema Bogu is njome povezanoj ljubavi prema bližnjemu. Međutim, kršćani uvijek moraju biti svjesni da su takva djela ljubavi duboko ukorijenjena i motivirana našom primarnom ljubavlju prema Bogu, Stvoritelju neba i zemlje, kao reakcija štovanja zbog Njegove vječne zavjetne ljubavi prema nama u Kristu.

\section{Treba li Crkva voljeti svijet ljudske kulture?}

Ključno pitanje o tome kako se Božji zavjetni narod treba odnositi prema širem svijetu naroda i kultura postavlja se od vremena biblijskog Izraela sve do danas. S jedne strane, kršćani mogu biti skloni izolirati se od šire kulture i zajednice, što je stav koji često nalazimo u semignostičkom pogledu na stvorenje o kojem smo govorili, ili pak smatrati svoju kulturu, odnosno subkulturu, nekako superiornijom nad ostalima. S druge strane, neki izričaji idu toliko daleko u prihvaćanju šire kulture da gotovo i nema razlike između Crkve i same kulture. Zato kršćani moraju oprezno ploviti između polugnostičke izolacije i eskapizma, koji podcjenjuje Božji stvoreni poredak i teološku obvezu da budemo sol i svjetlost svijetu, i haridbe kompromisa s duhom današnjice i korespondirajućih duhovnih sila koje Pismo povezuje sa svijetom duhovne pobune protiv Boga.

Podtočka B) sedme točke CIOP-a ističe da smo pozvani voljeti "Božji svijet naroda i kultura". I samo stvorenje izvan ljudskog roda ispoljava posljedice pada - nasilje, bolest, smrt, korupciju - ove su posljedice u biblijskoj pripovijesti ishod grešnosti ljudi, a ne stvorenja izvan ljudskog roda. Tako ljudi, kao korporativna jedinka, ne samo da ispoljavaju posljedice pada nego su i sami krivi za takvo stanje. Tako ljubav prema drugim ljudskim bićima mimo Krista podrazumijeva ljubav prema nečemu što je u grijehu i u stanju pobune. Međutim, znači li voljeti ljudske narode i kulture isto što i voljeti bližnjega, samo u kolektivnom smislu? Bog je obećao Abrahamu da će u njemu blagosloviti "sva plemena na zemlji” (Post $12,3)$, a ova tema o Izraelu kao posrednici YHWH pred narodima proteže se kroz proročke spise (Iz 2,2-4; Jer 4,1-2; Zah 8,20-23), a u punini se izražava u novom savezu u Mesiji Isusu (Mt 28,16-20; Dj 1,8). Međutim, bilo kakva ljubav u ovom biblijskome teološkom obećanju usmjerena je k ljudima u tim narodima, gdje je konačni cilj njihova pokornost Izraelovu Bogu, a ne ljubav prema samim nacionalnim entitetima koja je predstavljena u njihovim političkim i kulturološkim izričajima. Kao i sa svijetom stvorenja izvan ljudskog roda, u Bibliji ne nalazimo zapovijed da trebamo voljeti kolektivne ljudski konstruirane entitete; štoviše, kao što smo vidjeli prije, Bog je u ovom dobu privremeno dopustio zemaljskim naro- 
dima i kraljevstvima da operiraju pod vladavinom đavolskih moći. ${ }^{13}$

Još je teže pokušati razumjeti kako bi kršćani mogli voljeti ljudske kulture. ${ }^{14}$ Koliko god se trudili, u našim prevedenim Biblijama nećemo naići na riječ "kultura". Razlog je u tome što se radi o relativno novom pojmu koji se odnosi na ljudsko društvo. Jedna od najboljih konciznih definicija "kulture" jest ona koju je iznio Robert Redfield (1941, 132): ${ }^{15}$ "Kad govorimo o 'kulturi', imamo referencu na konvencionalno shvaćanje, djela i artefakte koji karakteriziraju društvo. Ova "shvaćanja" su značenja koja pripisujemo postupcima i predmetima... Koji su postali tipični za pripadnike toga društva posredstvom međusobne komunikacije." ${ }^{16}$ Ovoj definiciji možemo dodati spoznaje Vanhoozera $(2007,26)$, koji sugerira da su "djela i svjetovi značenja" rezultat slobodnih ljudskih odabira, a ne njihovih nagona. ${ }^{17}$ Ova razmišljanja o kulturi na koristan način diferenciraju "kulture" od samih ljudi. Kultura nije ljudsko biće, čak niti grupa ljudi, nego kolektivni skup shvaćanja i značenja koju grupa ljudi slobodno bira i dijeli, a koja se povezuju s (ili možda izražavaju u) onime što čine i stvaraju. S time na umu, možemo ustvrditi da netko može voljeti drugu osobu ili čak skupinu ljudi, a u isti mah odbacivati i izričito ne voljeti neke ili brojne aspekte njihove "kulture".

Tako u biblijskim i drugim drevnim tekstovima "kulturu" možemo prepoznati u uvriježenim značenjima koja ljudi pridaju svojim tradicijama, religijama, društvenim običajima, literaturi, umjetnosti i simbolima. Kao što smo vidjeli ranije, nigdje u Bibliji se Božjem narodu ne zapovijeda da voli običaje i tradicije takvih kolektivnih kultura. Doista, u Starom je zavjetu ljubav prema stranim običajima i njihovo prisvajanje vodilo u grijeh i idolopoklonstvo te je

13 U Novom zavjetu nalazimo jedan odjeljak gdje se opisuje ljubav prema narodu. Luka u svojem Evanđelju piše da su židovski poglavari u Kafarnaumu molili Isusa da pomogne rimskom stotniku jer "voli naš narod", agapa gar to ethnos hēmōn (Lk 7,5), što je ljubav koja se naoko očitovala u izgradnji sinagoge. Stotnik je očito bio bogobojazan čovjek koji je pokazivao svoju ljubav prema židovskom narodu, a vjerojatno i prema njihovu Bogu, postupkom davanja. Naratorski je sud ovdje očekivano pozitivan. Međutim, teško je zamisliti suprotnu situaciju, gdje bi narator imao pozitivan sud o Židovu ili ranom kršćaninu koji bi pokazivao ljubav prema Rimu izgradnjom poganskog hrama. Takav bi postupak jamačno bio osuđen.

14 Jasno je da tema kršćanstva i kulture zavrjeđuje mnogo više prostora nego što joj ga ovdje mogu pružiti, a literature o njoj je mnogo. Među klasičnim djelima, koja govore o njoj, jesu Newbigin (1986), a posebno Niebuhr (1951), čiji je rad revidirao Carson (2008). Na hrvatskom potražite novija Šimićeva djela (2018).

15 Navedeno u kraćem obliku kod Carsona $(2008,2)$.

16 Ideja o "angažiranosti" u kulturi vrlo je prisutna u današnjem diskursu, ali čak ni urednici novijeg djela pod naslovom "Engaging Culture" (Uključivanje u kulturu) pitaju je li "kultura" nešto u što je moguće "uključiti se", kao da smo neutralni promatrači (Chatraw i Prior 2019, 21). Umjesto toga, objašnjavaju da smo svi uronjeni u kulturu, tj., bili toga svjesni ili ne.

17 Novije definicije potražite kod Chatraw i Prior $(2019,24)$. 
bilo izričito zabranjeno. ${ }^{18}$ Vjernike se u Novom zavjetu upozorava da ne trebaju voljeti "svijet", odnosno ideju kosmosa o kojoj smo ranije govorili, koju sada možemo adekvatnije povezati sa sferom ljudskih struktura vlasti, naroda i kultura.

Ipak, ni proučavanje drevnih biblijskih konteksta obaju zavjeta ne otkriva da biblijski Izrael ni judaizam drugoga Hrama ni rano kršćanstvo nisu postojali u kulturološkom vakuumu. To jest, njihove kulture već su bile uronjene u različite kulture toga doba i mjesta, unutar kojeg su trebale ostati vjerne Bogu. ${ }^{19}$ Tako se određeni aspekti onoga što bismo mogli nazvati "kulturom" u ranoj Crkvi mogu otpisati i odbaciti, odnosno možemo im se diviti, prihvatiti ih i transformirati, ovisno o tome u kojoj mjeri su se prilagodili učenju Evanđelja. Kršćanstvo je, kako je uvaženi afrički teolog Lamin Sanneh $(2015,1)$ uvjerljivo ustvrdio, prevedena vjera, koja je od svojih početaka relativizirala aspekte svojeg korijena u hebrejskoj kulturi, a druge zagovarala, te je odbacivala aspekte poganskih kultura, dok je destigmatizirala druge. Nijedno kulturološko značenje u djelu i artefaktu se, stoga, ne može prihvatiti u cjelini, ali djela i artefakti, koji se mogu usvojiti i transformirati unutar kršćanskog načina shvaćanja, mogu se prisvojiti u službi Evanđelja (Dj 17,28). Očekivano, autoritativno učenje starozavjetnih Pisama i učenje Isusa i apostola bili su odlučujući čimbenici i nikakav kulturološki izričaj se nije tako mogao shvatiti kao sam po sebi superioran nad drugima, čak onaj židovski koji je formirao korijene kršćanstva (Dj 10,34; Rim 2,10-11). I, zbilja, Isus strogo kritizira židovske poglavare zbog uzdizanja "ljudskih predaja" iznad otkrivenih Božjih zapovijedi (Mk 7,1-13).

Navodeći primjer iz 4. stoljeća, Jaroslav Pelikan (1993, 18-21) ističe neodlučnost kapadocijskih otaca glede klasične grčke literature i filozofije u kojima su bili kulturološki odgojeni. S jedne strane, mogli su govoriti o Homerovim "demonskim mitovima", dok su ga, s druge strane, mogli s divljenjem citirati, odnosno i sami su mogli kao kršćanski neoplatonisti ipak žestoko opominjati na kaljanje kršćanskih istina takvim "bezbožnim filozofijama". Premda su se možda divili ili čak bili naklonjeni nekim aspektima kulturne tradicije, teško da je to bila

18 Dakako, kao što Chatraw i Prior $(2019,36)$ ističu, treba razmotriti cjelokupnu biblijsku priču. U kontekstu progona, recimo, potpuno odvojenje teško da je bilo moguće, zbog čega Jeremija 29 upućuje Židove da se utvrde unutar Babilona, da izgrade domove i obitelji te da teže dobrobiti grada u koji su prognani. Jasno, Jeremija nije rekao prognanicima da kapituliraju pred babilonskom kulturom i religijom, a židovska je povijest primjer naroda koji je postao vješt u očuvanju ključnih aspekata svog načina života čak i kad je doživljavao procvat u tuđoj zemlji. Situacija s prognanicima u Jeremiji umnogome je bila nagovještaj tenzija s kakvima će se kršćani susretati kako se Crkva bude širila među raznim narodima svijeta.

19 Čak i drevni Izrael treba promatrati unutar šireg konteksta bliskoistočne kulture (vidi Walton 2018). Vidi osobito Hurtado (2016) za susrete ranog kršćanstva s grčko-rimskom kulturom. 
ljubav u biblijskom smislu. Na koncu, kulture nisu ljudi, a uvriježena značenja kultura mimo Krista mogu se pozitivno cijeniti i prihvaćati samo u ograničenom smislu, odnosno može ih se promatrati negativno i odbaciti.

Prema novom savezu, nijedna narodnost niti država ne predstavlja Božji narod te su, shodno tomu, kršćani cijelog svijeta nužno pripadnici ljudske kulture i konkretnih ljudskih kultura, čijem razvoju doprinose u određenoj mjeri, bilo aktivno ili pasivno. Budući da se, kao što smo vidjeli, kultura sastoji od uvriježenih značenja, kršćani nisu pozvani da vole svoju kulturu, koliko da joj doprinose na način koji će proslaviti Boga (Mt 5,13-16), i kada podižu učenike unutar kulture, ali i onda kad doprinose uvijek rastućim i promjenjivim sustavima uvriježenih mišljenja unutar određene grupe ljudi, pritom ne kompromitirajući istinu Evanđelja. Time ne želimo reći da je cilj Evanđelja postići potpunu kulturološku transformaciju u ovom vremenu jer do potpune kulturološke transformacije može dovesti jedino Bog u novom stvorenju i vremenu koje treba doći. Međutim, Crkva koju vodi Sveti Duh treba biti iščekujuća manifestacija novoga doba u svojim interakcijama s ljudima i njihovim kulturama unutar sadašnjega zlog vremena (Ef 5,15; Kol 4,5-6). Kršćani, stoga, moraju shvatiti da već pripadaju kulturi i da su samim time dužni doprinositi joj i oblikovati ju u svjetlu Evanđelja (Newbigin 1986, 129).

Evanđelje je Božja poruka o ponovnoj uspostavi Njegove vladavine nad stvorenjem u otkupljujućoj Kristovoj ljubavi prema grešnicima u vidu Njegova života, smrti i uskrsnuća. Nadalje, Kristovo je spasiteljsko djelo dostupno svima neovisno o nacionalnoj, rasnoj, rodnoj i kulturološkoj pripadnosti; svi su "jedno u Kristu" (Gal 3,28). Ipak, Pismo jasno govori da će narodi i njihovi putovi biti podvrgnuti Isusovom disciplinskom autoritetu (Ps 2,8; 94,10; Mt 28,19). Ovdje možemo shvatiti narode (grčki: ethnē) kao "cijelo čovječanstvo" (Nolland 2005, 1266), a ne kao pojedinačne narode. I premda proces podizanja učenika u svim narodima treba biti motiviran istom onom požrtvovnom ljubavlju prema pripadnicima svih naroda, koju vidimo u Kristovoj požrtvovnoj ljubavi, ne možemo voljeti ove narode i kulture kao kolektivne cjeline u biblijskom smislu selektivnog, predanog i srdačnog odnosa prema drugima jer te cjeline nisu osobe. ${ }^{20}$

CIOP u točki E) upozorava na grešni, sotonski svijet koji ne treba voljeti,

20 Ne želim ovdje reći da ljudi ne trebaju "voljeti”, u prenesenijem smislu, izvjesne kulture ili njihove aspekte, tj., izvjesne osobine, karakteristike itd. Međutim, takva "ljubav" sličnija je sklonosti ili preferenciji, a ne selektivnoj, predanoj, k djelima orijentiranoj biblijskoj ljubavi koju CIOP spominje u imperativu. Međutim, čak i kad je riječ o takvoj sklonosti ili preferenciji, uvijek postoji opasnost da se ona pretvori u idolopokloničku ljubav ili naklonost, osobito kad se nacionalistička "ljubav" isuviše razbukti. S druge strane, Krist ne poziva pripadnike svih naroda na bezlični konformizam. Bog će, svakako, otkupiti brojne aspekte raznih ljudskih kultura kako bi one procvjetale u ljepoti Njegova novog stvorenja. 
ali nisam uvjeren da dokument u dovoljnoj mjeri objašnjava problematiku. Koje aspekte ljudske nacionalne, etičke i političke / ideološke kulture možemo kao kršćani s pravom cijeniti, usvojiti i voljeti, a koje ne? Svi su ljudi stvoreni na Božju sliku i svi u grijehu i stanju aktivne pobune protiv Boga, da nije Božje milosti. Shodno tomu, u svakoj kulturi možemo prepoznati elemente Božje istine, ljepote i mudrosti iako je svaka ljudska kultura koja je bez Krista u grešnoj pobuni protiv Boga. ${ }^{21}$ Ponovimo: voljeti "kulturu" ne može značiti ljubav prema grupi ljudi, nego ljubav prema njihovim uvriježenim, stvorenim životnim značenjima izraženima u djelu i artefaktu. Kršćani ne mogu voljeti takva uvriježena mišljenja ako su protivna Božjem otkrivenju. Međutim, kršćani jesu pozvani voljeti ljude iz svih naroda i kultura. I, zbilja, Isusov radikalni poziv na ljubav prema bližnjemu, čak i kad je u pitanju neprijatelj, i na ljubav prema najslabijima čak i kad oni ne mogu uzvratiti ljubav (Lk 10,25-37) usmjerava našu ljubav k ljudskim bićima upravo zato što su ona stvorena na Božju sliku. U pitanju je Evanđeljem oblikovana ljubav koja nadilazi prirodnu ljubav ljudskih bića.

$\mathrm{Na}$ koncu, kršćanima je u Pismu izričito zapovjeđeno jedino da vole svoje bližnje iz svih naroda i kultura, ali ne i kolektivne manifestacije tih naroda i kultura. Međutim, kao što smo ranije opisali zavisnu ljubav prema stvorenju izvan ljudskog roda, tako možemo konstruirati i zavisnu ljubav prema narodima i kulturama u vidu iskrenog stava predanosti i popratnih djela koja doprinose razvoju naroda i kulture u skladu s Evanđeljem, kao i sklonost prema onim aspektima kulture koji odražavaju ljepotu i mudrost Božjega stvorenog poretka koji se manifestira u ljudskoj kreativnosti, a ukorijenjen je i ovisan o našoj primarnoj, predanoj relacijskoj ljubavi prema Bogu i o s njoj povezanom ljubavlju prema bližnjemu.

\section{Zaključak}

U kontinuitetu s otkrivenjem starozavjetnih Pisama, Isus nam zapovijeda da volimo Boga i da volimo svojeg bližnjeg, tvrdeći da o ovim dvjema zapovijedima ovise sav zakon i proroci (Mt 22,37-40). Neodvojivost ljubavi prema Bogu i prema bližnjemu vrlo je očita u Svetom pismu, premda se, nažalost, često ignorira. Isusovo učenje o tome da nam naš bližnji čak može biti i neprijatelj oblikuje kršćanski pogled na svijet. Premda se kršćani moraju odupirati intimnim odnosima koji ih odvlače u grijeh, ipak moraju ostati nepokolebljivi u Gospodnjem poslanju da

21 Ovdje nisam u prilici baviti se pitanjem može li kultura biti "kršćanska" (vidi Eliot 2014). Međutim, čak i kad bi mogla biti, ne vjerujem da bi kršćani trebali voljeti tu "kulturu", nego Boga i druge vjernike koji pripadaju kulturi. Utoliko ukoliko možemo smatrati bilo koju kulturu "kršćanskom", kušnja za njezinom idolizacijom bila bi vrlo snažna, a takva bi idolizacija dovela do potkopavanja onoga što ju je i učinilo kršćanskom. 
vole sva ljudska bića kao svoje bližnje, svjesni da su i oni načinjeni na Božju sliku. Jasno, ne znači da će kršćaninova ljubav prema bližnjemu uvijek biti uzvraćena, a ljubav koja je uvjetovana Božjom ljubavi i željom da i drugi upoznaju Božju ljubav čak može izazvati i negativne reakcije u široj kulturi, međutim, kršćani moraju ustrajati u ljubavi jer su Isusovi sljedbenici. U zaključku, ljubav prema stvorenju izvan ljudskog roda i prema ljudskoj kreativnosti izražena u narodima i kulturama može, u najboljem slučaju, biti zavisna ljubav koja proistječe iz duboke ljubavi prema Bogu i prema ljudima. Ključno je da vjernici shvate sveobuhvatnu pripovijest Svetog pisma: da je Crkva, ujedinjena s uskrslim Kristom i osnažena Svetim Duhom, Božja iščekujuća zajednica novog stvorenja i novoga doba unutar sadašnjega posrnulog stvorenja i sadašnjega zlog doba duhovne pobune. Svijet je u konačnici Božji i Bog će ga u potpunosti uspostaviti i obnoviti u Kristu.

\section{Literatura}

Brown, Colin. 1986. " $\varphi \iota \lambda \dot{\varepsilon} \omega$. . U New International Dictionary of New Testament Theology, edited by Colin Brown, 2:547-50. Grand Rapids: Zondervan.

Capetownski iskaz o predanju (CIOP). Kairos: Evanđeoski teološki časopis, V. (2011), 1: 167-226

Carson, D. A. 2000. “Love." In New Dictionary of Biblical Theology, urr. T. Desmond Alexander and Brian S. Rosner, 646-50. Downer's Grove, IL: InterVarsity Press.

Carson, D. A. 2008. Christ and Culture Revisited. Nottingham: Apollos.

Chatraw, Joshua, i Karen Swallow Prior, urr. 2019. Cultural Engagement: A Crash Course in Contemporary Issues. Zondervan Academic.

Eliot, T. S. 2014. Christianity and Culture. San Diego: Harcourt Brace Jovanovich.

Fabry, H. J., i N. van Meeteren. 2006. “Tēbeēl; Tebel.” U Theological Dictionary of the Old Testament, urr. G. Johannes Botterweck, Helmer Ringgren, i Heinz-Josef Fabry, prev. David E. Green, 15:557-64. Grand Rapids: Eerdmans.

Glueck, Nelson. 1967. Hesed in the Bible. Cincinnati: Hebrew Union College Press.

Günther, W., and H. G. Link. 1986. “ảyatáw.” U New International Dictionary of New Testament Theology, edited by Colin Brown, 2:538-47. Grand Rapids: Zondervan.

Hurtado, Larry W. 2016. Destroyer of the Gods: Early Christian Distinctiveness in the Roman World. Baylor University Press.

Moo, Douglas J. i Jonathan A. Moo. 2018. Creation Care: A Biblical Theology of 
the Natural World. Biblical Theology for Life. Grand Rapids: Zondervan Academic.

Moo, Jonathan A. i Robert S. White. 2014. Let Creation Rejoice: Biblical Hope and Ecological Crisis. Downer's Grove, IL: IVP Academic.

Newbigin, Lesslie. 1986. Foolishness to the Greeks: The Gospel and Western Culture. London: SPCK.

Niebuhr, H. Richard. 1951. Christ and Culture. New York: Harper and Row.

Pelikan, Jaroslav. 1993. Christianity and Classical Culture: The Metamorphosis of Natural Theology in the Christian Encounter with Hellenism. New Haven: Yale University Press.

Pennington, Jonathan T. 2009. Heaven and Earth in the Gospel of Matthew. Reprint edition. Grand Rapids: Baker Academic.

Redfield, Robert. 1941. The Folk Culture Of Yucatan. http://archive.org/details/ in.ernet.dli.2015.233906.

Routledge, Robin. 1995. “Hesed as Obligation: A Re-Examination.” Tyndale Bulletin 46 (1): 179-96.

Routledge, Robin. 2012. Old Testament Theology: A Thematic Approach. Downer's Grove, IL: IVP Academic.

Sanneh, Lamin. 2009. Translating the Message: The Missionary Impact on Culture. 2nd edition. Maryknoll, NY: Orbis.

Šimić, Krešimir. 2018. Rađanje kulture. Zagreb: Naklada Breza.

Snaith, Norman H. 1964. The Distinctive Ideas of the Old Testament. New York: Schocken.

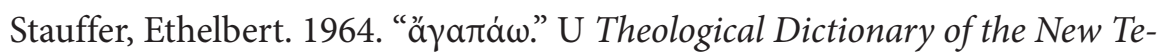
stament, urr. Gerhard Kittel, prev. Geoffrey W. Bromiley, 1:35-55. Grand Rapids: Eerdmans.

“The Cape Town Commitment." Lausanne Movement. Pristupljeno 20 ožujka 2020 https://www.lausanne.org/content/ctcommitment\#p1-7

Vanhoozer, Kevin J. 2007. "What Is Everyday Theology? How and Why Christians Should Read Culture." U Everyday Theology: How to Read Cultural Texts and Interpret Trends, urr. Kevin J. Vanhoozer, Charles A. Anderson, i Michael J. Sleasman, 15-62. Cultural Exegesis. Grand Rapids: Baker Academic.

Waltke, Bruce K. 2001. Genesis: A Commentary. Grand Rapids: Zondervan.

Walton, John H. 2018. Ancient Near Eastern Thought and the Old Testament: Introducing the Conceptual World of the Hebrew Bible. Grand Rapids: Baker Academic. 
Wright, Christopher J. H. 1997. “Tēbeêl.” U New International Dictionary of Old Testament Theology and Exegesis, ur. Willem A. VanGemeren, 4:272-73. Grand Rapids: Zondervan.

Preveo s engleskog Davor Edelinski

Gregory S. Thellman

\title{
Should the Church Love the (God's) World? A Response to the Cape Town Commitment Point Seven
}

\begin{abstract}
This paper is a response to point seven, sub-points A) and B) of the Cape Town Commitment (CTC), and attempts to answer the question "is love the proper Christian response to the nonhuman creation, and/or to human nations and culture?" Based on a summary of the concepts of "love" and the "world" in the biblical texts, it is shown that the biblical concept of "love" strongly emphasizes heartfelt and caring commitment for another within human relationships and divine-human relationships. The "world" in Scripture can be construed in positive, neutral or negative senses, depending on the term and context, and Christians find themselves both in a fallen creation which awaits liberation and within human nations and cultures in a state of sin and rebellion against God. While the Bible never commands believers to love the nonhuman creation or collective human entities like nations and cultures, Christians may yet appropriate love for God and neighbor through their attentive care of creation and through their contribution to culture in a way that glorifies God. In these ways, Christians may "love" creation and culture, but only in a contingent sense with their foundational love focused on God and neighbor.
\end{abstract}

